\title{
Treatment of retinal tears and lattice degenerations in fellow eyes in high risk patients suffering retinal detachment: a prospective study
}

Leonardo Mastropasqua, Paolo Carpineto, Marco Ciancaglini, Gennaro Falconio, Pier E Gallenga

\begin{abstract}
Backgroundlaims-Fellow eye prophylaxis for retinal detachment (RD) is still a controversial issue since opinions are not unanimous regarding the kind of lesions to be treated or the method of treatment. This prospective clinical study aimed to follow the course of vitreoretinal conditions in 150 high risk fellow eyes.

Methods-150 consecutive patients with unilateral rhegmatogenous $\mathrm{RD}$ were included in this study. Inclusion criteria were good explorability of fellow eye retinal periphery and one of the following conditions in the fellow eye-aphakia, pseudophakia with capsulotomy, high myopia (>-6D), contralateral eye to a giant retinal tear. Prophylactic treatment (photocoagulation or scleral buckling) was performed in the presence of retinal tears and lattice degenerations. The state of the vitreous body was determined at the beginning of the study and at the end, when RD occurred.
\end{abstract}

Results-Follow up ranged from 36 to 132 months. 95 fellow eyes were subjected to laser treatment; five eyes underwent prophylactic surgical treatment. Initially, in the treated group posterior vitreous detachment (PVD) was present in 100 eyes (100\% of cases), but as a complete PVD only in 42 of them (42\%). 10 eyes in the treated group developed $\mathrm{RD}$ during the follow up period. In five of these cases the partial PVD had progressed and a retinal tear in a previously healthy area was the cause of the retinal detachment. In the other five eyes RD apparently developed from previously treated lesions. Progression of PVD was evident in four out of these five eyes. The untreated eyes had no visible degenerative lesions. During follow up eight eyes developed RD. These eyes had no PVD at the beginning of the study, but showed a partial PVD at the time of the diagnosis of RD.

Conclusion-Fellow eyes with pre-existing retinal tears and PVDs can go on to retinal detachment in spite of laser prophylactic treatment. When PVD is not detectable or a partial PVD is present, the progression of posterior vitreous separation can account for retinal tears and RDs arising in formerly healthy areas. (Br f Ophthalmol 1999;83:1046-1049)
Many studies of posterior vitreous detachment (PVD) have helped to state the role of PVD in determining tractional retinal tears and subsequent retinal detachments. ${ }^{1-11}$ Treatment of symptomatic tractional retinal tears is a largely accepted concept. Controversy arises when retinal breaks are discovered not in association with a recent history of symptoms. ${ }^{12}$

Reviewing the usefulness of prophylaxis, Byer $^{12}$ states that ophthalmologists should regard most fellow eye retinal detachment as unpreventable events; in fact, a majority (about $58 \%$ ) of retinal tears and detachments develop in eyes showing no visible vitreoretinal abnormalities. In addition, treatment of visible lesions may modify the natural history of PVD by increasing vitreoretinal traction at unknown locations. ${ }^{12}$

This prospective, clinical study was designed to follow the course of vitreoretinal conditions in 150 high risk fellow eyes.

Subjects and methods

This study consisted of 150 consecutive patients who had been operated on for retinal detachment (RD) at our institute from January 1987 to December 1994. Inclusion criteria were unilateral retinal detachment, good explorability of fellow eye retinal periphery, and one of the following conditions in the fellow eye-aphakia, pseudophakia with capsulotomy, high myopia (>-6D), contralateral eye to a giant retinal tear. Table 1 shows the details of our sample of patients.

A complete retinal examination of fellow eyes was performed using binocular indirect ophthalmoscopy, combined with scleral indentation throughout $360^{\circ}$. This was followed by slit lamp examination with a Goldmann three mirror contact lens. The presence of a detached posterior hyaloid membrane in addition to the usual, though not invariable, presence of a prepapillary glial ring or tissue were the basis for the diagnosis of PVD. The separation of the vitreous body and retina up to

Table 1 Patient characteristics

\begin{tabular}{ll}
\hline Number of patients & $150(\%)$ \\
\hline Men & $98(65.33)$ \\
Women & $52(34.67)$ \\
& $59.8(22-83)$ \\
\hline Risk factors & No of eyes (\%) \\
\hline High myopia & $90(60)$ \\
Aphakia & $38(25.33)$ \\
Pseudophakia with capsulotomy & $17(11.33)$ \\
Contralateral to giant retinal tear & $5(3.33)$ \\
\hline
\end{tabular}

Accepted for publication 29 April 1999 
Table 2 State of the vitreous body at the beginning of the study as determined using both biomicroscopic and ultrasonic criteria

\begin{tabular}{lll}
\hline & \multicolumn{2}{l}{ No of eyes } \\
\cline { 2 - 3 } State of the vitreous body & Treated group & Untreated group \\
\hline Absence of PVD & 0 & 38 \\
Partial PVD & 58 & 10 \\
Complete PVD & 42 & 2 \\
\hline
\end{tabular}

Table 3 Relation between symptoms and age of patients

\begin{tabular}{llll}
\hline \multirow{4}{*}{$\begin{array}{lll}\text { No of eyes } \\
\text { Symptoms }\end{array}$} & $\begin{array}{l}\text { Age }<40 \\
\text { years }\end{array}$ & $\begin{array}{l}\text { Age 40-60 } \\
\text { years }\end{array}$ & $\begin{array}{l}\text { Age }>60 \\
\text { years }\end{array}$ \\
\hline Flashes & 3 & 8 & 2 \\
Floaters & 4 & 15 & 4 \\
Flashes and floaters & 13 & 29 & 6 \\
No symptoms & 0 & 0 & $11^{\star}$ \\
\hline
\end{tabular}

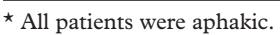

Table 4 Duration of symptoms

\begin{tabular}{llll}
\hline & \multicolumn{3}{l}{ No of eyes (\%) } \\
\cline { 2 - 4 } Symptoms & $<1$ week & $1-4$ weeks & $\begin{array}{l}>4 \text { weeks } \\
<3 \text { months }\end{array}$ \\
\hline Flashes & $11(84.6)$ & $2(15.4)$ & 0 \\
Floaters & $15(65.2)$ & $5(21.7)$ & $3(13.1)$ \\
Flashes and floaters & $40(83.3)$ & $8(16.7)$ & 0 \\
\hline
\end{tabular}

the posterior border of the vitreous base was defined as complete posterior vitreous detachment, while partial or incomplete PVD referred to a vitreous separation which had not progressed so far peripherally. ${ }^{67}$ The vitreous body and, in particular, the extension of posterior vitreous separation were also studied using $\mathrm{A}$ and B-scan echography. In the case of PVD, two holes in the posterior vitreous surface corresponding to the areas of the macula and the optic disc can be found. Using an A-scan technique with a $\mathrm{T}+9$ sensitivity a medium, low, or

Table 5 Retinal lesions laser treated in fellow eyes

\begin{tabular}{lll}
\hline & No of eyes & \\
\cline { 2 - 3 } Risk factors & Retinal tears & Lattice degeneration \\
\hline High myopia & 12 & 35 \\
Aphakia & 17 & 12 \\
Pseudophakia and capsulotomy & 7 & 8 \\
Contralateral to giant retinal tear & 2 & 2 \\
\hline
\end{tabular}

Table 6 Retinal lesions in fellow eyes undergoing surgery

\begin{tabular}{llll}
\hline & \multicolumn{2}{l}{ No of eyes } & \\
\cline { 2 - 4 } Risk factors & Giant tears & Multiple breaks & $\begin{array}{l}\text { Tears with initial RD } \\
\text { and PVR (B) }\end{array}$ \\
\hline High myopia & - & - & 2 \\
Aphakia & - & 1 & - \\
Pseudophakia and capsulotomy & - & 1 & - \\
Contralateral to giant retinal tear & 1 & - & - \\
\hline
\end{tabular}

Table 7 Risk factors for each group

\begin{tabular}{llll}
\hline \multirow{2}{*}{ Risk factors } & \multicolumn{2}{l}{ No of eyes (\%) } \\
\cline { 2 - 4 } & Laser treated group & Buckle treated group & Untreated group \\
\hline High myopia & $47(49.47)$ & $2(40)$ & $41(82)$ \\
Aphakia & $29(30.53)$ & $1(20)$ & $8(16)$ \\
Pseudophakia and capsulotomy & $15(15.79)$ & $1(20)$ & $1(2)$ \\
Contralateral to giant retinal tear & $4(4.21)$ & $1(20)$ & 0 \\
\hline
\end{tabular}

high reflective very mobile spike, showing "after movements", can be seen. ${ }^{13}$ The state of the vitreous body was determined at the beginning of the study and at the end, when RD occurred.

Prophylactic treatment was carried out whenever retinal tears and areas of lattice degeneration with microholes had been detected. The argon laser treatment was performed by applying laser burns in three continuous rows surrounding the lesion.

In some selected cases a silicone encircling band, scleral buckle, and cryotherapy were preferred. This method was reserved for high risk cases, such as eyes with multiple retinal degenerations larger than $90^{\circ}$, retinal dialysis, giant tears, multiple retinal tears in several quadrants, retinal tears with evident vitreoretinal traction, or large tears that had either rolled edges (PVR, stage B) or localised subretinal fluid surrounding the tear (subclinical RD). ${ }^{14}$

\section{Results}

Mean follow up was 69.4 months (range 36-132 months). At the beginning of the study the prevalence of PVD in the fellow eye was $74.67 \%$ (112 out of 150 eyes). A complete PVD was observed in only 44 of them (29.33\%). In all cases the biomicroscopic finding was confirmed by ultrasonic examination (Table 2).

In 95 cases prophylactic treatment with argon laser was carried out on fellow eyes. Eighty four out of 95 eyes $(88.42 \%)$ had symptoms before laser treatment. Thirteen patients (13.68\%) had only light flashes as a symptom, $23(24.21 \%)$ had only visual floaters, and 48 $(50.53 \%)$ reported both. The correlation between symptoms and age of patients is shown in Table 3. All these patients reported their symptoms for less than 3 months. The duration of symptoms is given in Table 4. All the eyes $(11$ out of $95,11.58 \%$ ) in which there were no symptoms were aphakic.

The predisposing lesions leading to the laser treatment are listed in Table 5. Eight eyes had retinal tears adjacent to lattice lesions. In these cases laser treatment was performed on the surrounding retinal tear and lattice degeneration areas.

In five cases it was deemed necessary to have a prophylactic treatment involving episcleral surgery and cryotherapy. All these eyes had light flashes and visual floaters as symptoms. Table 6 gives the features of the eyes treated with prophylactic surgery. The prevalence of risk factors among the three groups (laser treated, buckle treated, and untreated group) is shown in Table 7.

During follow up the incidence of fellow eye RD was $12 \%$ of cases (18 out of 150 eyes). Ten eyes had been subjected to laser treatment. In five of them ( $50 \%$ of cases) $\mathrm{RD}$ was linked to new retinal tears in previously healthy areas. In all these five cases a partial PVD had progressed and a horseshoe-shaped retinal tear was the cause of the retinal detachment. In two eyes the tear was near, but on the outside of the chorioretinal scar surrounding a previously treated lattice lesion. 
In the other five eyes $\mathrm{RD}$ apparently developed from previously treated lesions. In four cases a progression of PVD was evident and chorioretinal scars caused by laser treatment were able to limit the extension of the detached area. Three of these four eyes had been treated for retinal tears adjacent to lattice lesions. In one case laser treatment was not able to cause a firm chorioretinal adhesion and $\mathrm{RD}$ progressed to the macula despite the treatment. In this highly myopic patient a complete PVD was present at the time of laser treatment.

The time interval between the laser treatment and the onset of $\mathrm{RD}$ ranged from 2 months to 5 years.

None of the surgically treated eyes developed RD during the follow up period.

The eight of 50 untreated eyes $(16 \%$ of cases) that developed $\mathrm{RD}$ during follow up showed no visible degenerative lesions or PVD at the beginning of the study. Five of them were affected by high myopia, two eyes were aphakic, and one was pseudophakic with capsulotomy.

At the time of $\mathrm{RD}$ diagnosis all these eight eyes showed a partial PVD. Seven eyes developed RD from a horseshoe-shaped tear. In the other eye multiple roundish retinal holes in a lattice area were evident in the detached retina.

\section{Discussion}

The average true incidence of fellow eye retinal detachment is $4-14 \% .^{12-19}$ The literature contains a very broad range of bilaterality, as high as $35 \%$, but several authors $\mathrm{s}^{20-24}$ have pointed out correctly that specialised retinal centres tend to collect more complicated and serious cases and thus report a higher bilaterality rate.

In our study the total incidence of fellow eye retinal detachment was $12 \%$. If we consider only the laser treated group the incidence was $10.35 \%$ (10 out 95 eyes). Our results compare favourably with the percentages reported by other authors, ${ }^{18} 19$ but no comparison can be made with previously published articles in which the study design was different from ours.

Opinions vary a great deal as regards criteria for prophylaxis. The current scientific literature includes some authors still purporting that, in the prophylactic treatment of the fellow eye, ${ }^{2526}$ a $360^{\circ}$ laser cerclage is advisable, though many studies have recently highlighted the risks linked to this kind of treatment. ${ }^{12} 27-29$

Schroeder and Baden $^{30}$ found that $7.2 \%$ of eyes surgically treated for retinal detachment had been previously subjected to prophylactic photocoagulation because of lattice degeneration and retinal tears. The retinal lesions responsible for detachment were found within or at the border of the coagulation scars in $66 \%$ of cases. Byer ${ }^{12}$ reported that approximately $58 \%$ of rhegmatogenous $\mathrm{RD}$ occur in eyes that do not have visible predisposing retinal lesions; in addition, treatment of visible areas may increase invisible vitreoretinal traction and induce new retinal tears and $\mathrm{RDs}$ arising at unsuspected locations. Thus, the author believes that a symptomatic, tractional retinal tear is the only significant indication for prophylactic laser treatment.

We used to treat fellow eyes in the presence of retinal tears and/or areas of lattice lesions with microholes. Symptomatic recent retinal tears are the foremost indication for treatment. ${ }^{12}$ As stated by Hovland ${ }^{18}$ the risk of retinal detachment in the presence of visible lattice degeneration and posterior vitreous separation may remain high; holes of lattice degeneration may lead to clinical or subclinical retinal detachment in approximately $2 \%$ of involved people and account for 3\% of clinical RDs in general. ${ }^{31}$

Argon laser treatment is performed by applying laser burns in three continuous rows surrounding the lesions. In highest risk cases surgical prophylaxis is preferred. This method is usually reserved for eyes with multiple retinal degenerations larger than $90^{\circ}$, retinal dialysis, giant tears, multiple retinal tears in several quadrants, retinal tears with an evident vitreoretinal traction, or large tears having either rolled edges (PVR, stage B) or subclinical RD.

Sometimes laser treatment is not able to prevent either new breaks or RD. ${ }^{12} 193032$ In our study RD developed in 10 eyes previously laser treated and in eight eyes which did not show any lesion. In 13 out of 18 cases $(72.22 \%) \mathrm{RD}$ was linked to new retinal tears occurring ex novo in retinal areas previously free of clinically apparent vitreoretinal lesions.

The progression of posterior vitreous detachment in most of the eyes which developed fellow eye retinal detachment was the most interesting finding in this study. The crucial role of posterior vitreous detachment in determining the idiopathic retinal detachment was well known by Hruby in $1946 .{ }^{6}$ In his study of fellow eyes in aphakic retinal detachment Hovland ${ }^{18}$ related vitreous separation to retinal detachment. In his sample of the 40 patients who did not show PVD initially, 11 later developed symptomatic PVD and eight of them developed retinal detachment. In our sample 17 out of 18 patients who developed fellow eye retinal detachment showed an evident progression of PVD. Only one of the 44 eyes that showed complete PVD at the beginning of the study went on to RD.

In conclusion, the presence of symptomatic retinal lesions is widely accepted to be the foremost indication for treatment, but sometimes the mere recognition and treatment of risk areas in the fellow eye are not enough to prevent a further development of this pathology, which seems also to be linked to vitreoretinal conditions (PVD developing). Some of fellow eyes with pre-existing retinal breaks and partial PVD can go on to $\mathrm{RD}$, despite laser treatment.

When PVD is not detectable or a partial PVD has not yet progressed to a complete PVD, the possibility that retinal tears and RDs arise in areas which show no visible retinal abnormalities has to be strongly considered. In fact, in an unknown portion of the population there exist pathological vitreoretinal adhesions, most of which clinically are not visible or discoverable ${ }^{37}$; undetectable vitreoretinal adhe- 
sions become translated into vitreoretinal tractions at the time of PVD.

The effectiveness of prophylactic laser treatment in the fellow eye has not been universally proved and it is almost impossible to show that the formation of new retinal breaks after laser treatment has not been precipitated by the treatment itself.

In our sample laser barrage was capable of limiting $\mathrm{RD}$ in four out five $(80 \%)$ cases of $\mathrm{RD}$ originating from previously treated lesions. In addition, in two out of five $(40 \%)$ laser treated cases developing $\mathrm{RD}$ at a later stage as a result of retinal tears occurring in formerly healthy areas, the area involved in the laser barrage remained flat. One may affirm that such treatment could at least limit RD development; however, the possibility that the treatment itself played a part in causing the progression of PVD has to be evaluated.

1 Linder B. Acute posterior vitreous detachment and its retinal complications: a clinical biomicroscopic study. Acto Ophthalmol Suppl 1966;87.

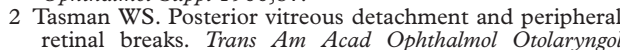
1968;72:217-24

3 Jaffe NS. Complications of acute posterior vitreous detachment. Arch Ophthalmol 1968;79:568-71.

4 Kanski JJ. Complications of acute posterior vitreous detachment. Am f Ophthalmol 1975;80:44-6.

5 Tabotabo MM, Karp LA, Benson WE. Posterior vitreous detachment. Ann Ophthalmol 1980;12:59-61.

6 Hruby K. Neuere Untersuchungsergebnisse zur Klinik und Pathologie des Glaskörpers. Wien klin Wschr 1946;58:461-

Hruby K. Die hintere Glaskörperabhebung mit Kollaps und periphere Netzhautdegenerationen als Ursache der idopathischen Netzhautablösung. Eine Zusammenschau klinischer Beobachtungen und anatomischer Studien. Klin Monatsbl Augenheilkd 1981;179:226-30.

8 Boldrey EE. Risk of retinal tears in patients with vitreous floaters. Am f Ophthalmol 1983;96:783-7.

9 Novak MA, Welch RB. Complications of acute symptomatic posterior vitreous detachment. Am f Ophthalmol 1984;97: 308-14.

10 Murakami K, Jalkh AE, Avila MP, et al. Vitreous floaters. Ophthalmology 1983;90:1271-6.

11 Byer NE. Natural history of posterior vitreous detachment with early management as the premier line of defense against retinal detachment. Ophthalmology 1994;101:150314 .

2 Byer NE. Rethinking prophylactic treatment of retinal detachment. In: Stirpe $M$, ed. Advances in vitreoretinal sur gery. Acta Third International Congress on Vitreoretinal Surgery. Rome, 12-14 September 1991. Ophthalmic Communications Soc, New York, 1992:399-411.

13 Gallenga PE, Cennamo G, Rosa N, et al. Echographic study of the vitreoretinal interface. In Stirpe M, ed. Advances in vitreoretinal surgery. Acta Third International Congress on Vitreoretinal Surgery. Rome, 12-14 September 1991 Ophthalmic Communications Soc, New York, 1992:107112
14 Davis MD. The natural history of retinal breaks without detachment. Trans Am Ophthalmol Soc 1973;71:343-72.

15 Dralands L, Larminier F, Cornelis $\mathrm{H}$, et al. Evolution des lesions de la peripherie de la retine dans l'oeil congenere d'un decollement retinien. Bull Mem Soc Fr Ophtalmol 1981;92:73-7.

16 Girard P, Goichot L, Saragoussi JJ, et al. Le devenir de l'oeil adelphe dans le decollement de retine-etude sur 1148 patients. 7 Fr Ophtalmol 1982;5:681-5.

17 Girard P, Boscher C, Merad I, et al. Le decollement de retine du dexieme oeil. Facteurs de risque. $\mathcal{F}$ Fr Ophtalmol 1983;6:975-9

18 Hovland KR. Vitreous findings in fellow eyes of aphakic retinal detachment. Am f Ophthalmol 1978;86:350-3.

19 Folk JC, Arrindell EL, Klugman MR. The fellow eye of patients with phakic lattice retinal detachment. Ophthalmology 1989;96:72-9.

20 Schepens CL, Marden D. Data on the natural history of retinal detachment. Arch Ophthalmol 1961;66:631-42.

21 Törnquist R. Bilateral retinal detachment. Acta Ophthalmol 1963;41:126-33

22 Davis MD, Segal PP, MacCormick A. The natural course followed by the fellow eye in patients with rhegmatogenous retinal detachment. In: Pruett RC, Regan CDJ, eds. Retina congress. New York: Appleton-Century-Crofts, 1974:64359.

23 Meyer-Schwickerath G, Fried M. Prophylaxis of retinal detachment. Trans Ophthalmol Soc UK 1980;100:56-65.

24 Haut J, Arne J, Khairallah M. La prevention du decollement idiopathique de la retine. Bull Soc Ophtalmol Fr 1988;88:1173.

25 Madelain J, Turut P. Resultats du traitement prophylactique systematique au laser argon apres decollement de retine idiopathique. Bull Soc Ophtalmol Fr 1990;90:141-7.

26 Haut J, Ladjimi A, Van Effenterre G, et al. Traitement prophylactique du decollement de retine de l'oeil adelphe. Resultats avec un recul de cinq ans, sur 109 yeux. $\mathscr{f} \mathrm{Fr}$ Ophtalmol 1991;14:397-404.

27 Vallat M, Detre J, Robin A. Avantages et dangers du cerclage prophylactique du decollement de la retine au laser a l'argon. Bull Mem Soc Fr Ophtalmol 1982;93:38-41.

28 Juillard G, Bacin F, Kantelip B, et al. Retraction retinienne gravissime apres cerclage prophylactique au laser a l'argon (a propos d'un cas). Bull Soc Ophtalmol Fr 1979;79:1073-6.

29 Bonnet $M$. Rhegmatogenous retinal detachment after prophylactic argon laser photocoagulation. In Stirpe M, ed. prophylactic argon laser photocoagulation. In Stirpe $\mathrm{M}$, ed. Congress on Vitreoretinal Surgery. Rome, 12-14 September 1991. Ophthalmic Communications Soc, New York, ber 1991. Oph

30 Schroeder W, Baden H. Netzhautablosung trotz vorbeugender Koagulation. Ophthalmologe 1996;93:144-8.

31 Byer NE. Long-term natural history of lattice degeneration of the retina. Ophthalmology 1989;96:1396-402.

32 Folk JC, Bennett SR, Klugman MR, et al. Prophylactic treatment to the fellow eye of patients with phakic lattice retinal detachment: analysis of failures and risks of treatment. Retina 1990;10:165-9.

33 Chignell AH, Shilling J. Prophylaxis of retinal detachment. Br f Ophthalmol 1973;57:291-8.

34 Robertson DM, Norton EWD. Long-term follow-up of retinal breaks. Am f Ophthalmol 1973;75:395-404.

35 Kanski JJ, Daniel R. Prophylaxis of retinal detachment. Am F Ophthalmol 1975;79:197-205.

36 Benson WE, Grand MG, Okun E. Aphakic retinal detachment. Management of the fellow eye. Arch Ophthalmol 1975;93:245-9.

37 Byer NE. Posterior vitreous detachment as a risk factor for retinal detachment (author's reply). Ophthalmology 1995; 102:527-8. 